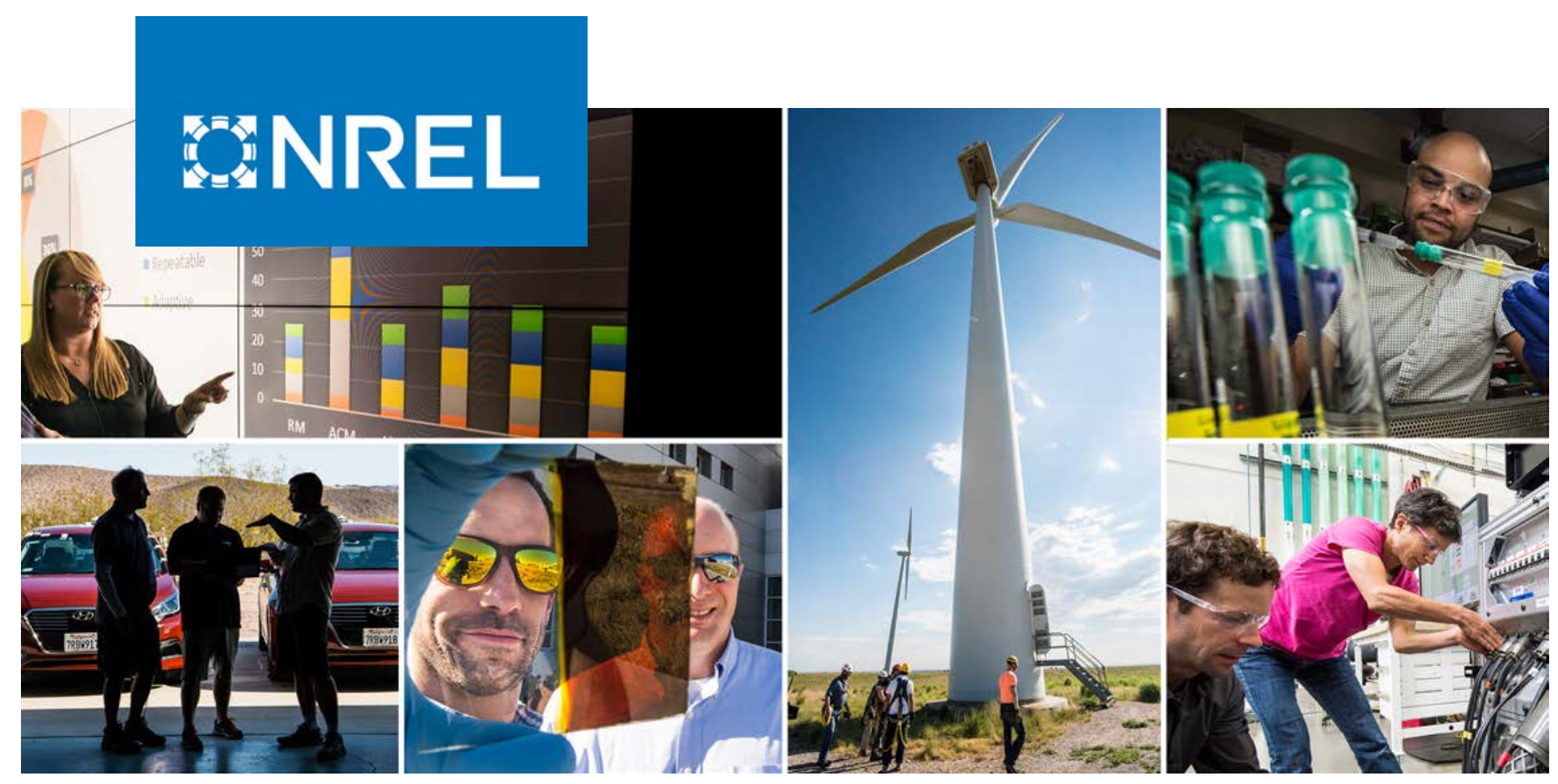

\title{
DNV GL Joint Industry Project on Validation of Turbulence Models
}

\section{Cooperative Research and Development Final Report}

CRADA Number: CRD-17-673

NREL Technical Contacts: Jason Jonkman and Paul Veers

NREL is a national laboratory of the U.S. Department of Energy Office of Energy Efficiency \& Renewable Energy

Operated by the Alliance for Sustainable Energy, LLC

This report is available at no cost from the National Renewable Energy Laboratory (NREL) at www.nrel.gov/publications.
Technical Report

NREL/TP-5000-73167

January 2019 


\title{
BNREL
}

\section{DNV GL Joint Industry Project on Validation of Turbulence Models}

\author{
Cooperative Research and \\ Development Final Report
}

CRADA Number: CRD-17-673

NREL Technical Contacts: Jason Jonkman

and Paul Veers

\section{Suggested Citation}

Jonkman, Jason and Paul Veers. 2019. DNV GL Joint Industry Project on Validation of Turbulence Models: Cooperative Research and Development Final Report, CRADA Number CRD-17-673. Golden, CO: National Renewable Energy Laboratory. NREL/ TP-5000-73165. https://www.nrel.gov/docs/fy19osti/73167.pdf.

NREL is a national laboratory of the U.S. Department of Energy Office of Energy Efficiency \& Renewable Energy Operated by the Alliance for Sustainable Energy, LLC

This report is available at no cost from the National Renewable Energy Laboratory (NREL) at www.nrel.gov/publications.

Contract No. DE-AC36-08GO28308
Technical Report NREL/TP-5000-73165 January 2019

National Renewable Energy Laboratory 15013 Denver West Parkway Golden, CO 80401 303-275-3000 • www.nrel.gov 


\section{NOTICE}

This work was authored by the National Renewable Energy Laboratory, operated by Alliance for Sustainable Energy, LLC, for the U.S. Department of Energy (DOE) under Contract No. DE-AC36-08GO28308. Funding provided by U.S. Department of Energy Office of Energy Efficiency and Renewable Energy, Wind and Water Technologies Office. The views expressed herein do not necessarily represent the views of the DOE or the U.S. Government.

This report is available at no cost from the National Renewable Energy Laboratory (NREL) at www.nrel.gov/publications.

U.S. Department of Energy (DOE) reports produced after 1991 and a growing number of pre-1991 documents are available free via www.OSTI.gov.

Cover Photos by Dennis Schroeder: (clockwise, left to right) NREL 51934, NREL 45897, NREL 42160, NREL 45891, NREL 48097, NREL 46526.

NREL prints on paper that contains recycled content. 


\section{Cooperative Research and Development Final Report}

In accordance with requirements set forth in the terms of the CRADA agreement, this document is the final CRADA report, including a list of subject inventions, to be forwarded to the DOE Office of Science and Technical Information as part of the commitment to the public to demonstrate results of federally funded research.

Parties to the Agreement: Det Norske Veritas, Danmark A/S (DNV GL)

CRADA number: CRD-17-673

CRADA Title: DNV GL Joint Industry Project on Validation of Turbulence Models

Joint Work Statement Funding Table showing DOE commitment:

\begin{tabular}{|c|c|}
\hline Estimated Costs & \multicolumn{2}{|c|}{ NREL Shared Resources } \\
a/k/a Government In-Kind \\
\hline Year 1 & $\$ 20,000.00$ \\
\hline Year 2 & $\$ 55,171.00$ \\
\hline Year 3 & $\$ 46,026.00$ \\
\hline TOTALS & $\$ 121,197.00$ \\
\hline
\end{tabular}

Abstract of CRADA Work:

This shared resource CRADA defines research collaborations between the National Renewable Energy Laboratory (NREL) and Det Norske Veritas (Norway) and Germanischer Lloyd (Germany), known as DNV GL, an international certification body. Under the terms and conditions described in this CRADA agreement, NREL will participate in a wind turbine Joint Industry Project (JIP) led by DNV GL, and including nine other Joint Industry Project sponsors and partners to examine the wind inflow models needed to define the design conditions for wind turbines, with specific focus on atmospheric turbulence.

The international design standards are implemented by certification companies, such as DNV GL, the organizing agent of the JIPs. Through this collaboration, the JIP participants have the ability to improve wind turbine design, internationally, as well as in the United States, and can make this improvement by leveraging the significant aggregation of industry funds that has been organized by DNV GL. 


\section{Summary of Research Results:}

The aim of the DNV-GL-led JIP was to validate turbulence models (Mann and Veers) used in existing international wind turbine design standards (e.g. IEC 61400-1) at the heights and scales of modern utility-scale turbines and to gain a deeper understanding of the influence of sitespecific ambient wind turbulence on wind turbine loading and performance.

The JIP focused on the following three work packages:

- WP 1. Collect existing wind data from different sites: This first work package aimed to collect as much wind measurement as possible for different type of sites, including simple onshore sites, onshore sites in complex terrain, nearshore sites, and offshore sites. NREL contributed by providing raw measurement data over a 13-month period from the NREL/NWTC M5 met-tower at $20 \mathrm{~Hz}$ from sonic anemometers at multiple heights.

- WP 2. Post-Processing of wind data and validation of turbulence models: This second work package aimed to obtain information on key turbulence parameters, to verify that the modified turbulence model represents the wind measured, and to provide representative valid ranges of key turbulence parameters for WP 3. NREL contributed by (a) participating in a round-robin exercise to ensure that the measurement data postprocessing scripts used by all participants (for data cleaning, statistics, spectral fitting, etc.) were well aligned and (b) by processing the measurement data from the NREL/NWTC M5-met tower into 10-minute-average, derived parameters such as atmospheric stability, turbulent length scale, turbulence intensity, wind shear, air density, and Mann-model parameters.

- WP 3. Load Simulations - Sensitivity Analyses: This third work package aimed to investigate what the load impact is when turbulence models are modified based on sitespecific conditions. NREL patriated by using an OpenFAST model of the NREL 5-MW turbine and running a series of aero-elastic simulations to (a) assess the impact of sitespecific wind conditions for different atmospheric stabilities (neutral, stable, unstable) on wind turbine fatigue loads compared to loads obtained using IEC-recommend values and (b) compare the difference between loads generated by the Mann and Veers turbulence models.

NREL also (a) attended a series of net-meetings and three physical meetings in Denmark to review the project progress and guide the next steps and (b) provided review comments on the project final report. The final project report will be published as an internal DNV-GL report (shared with the project participants) later this year.

Due to time constraints, many of the objectives that were originally proposed for the project were not met; however, the large database of processed wind measurements at various sites is of great value. As such, a follow-on project is planned for initiation in late 2018 to use the database of wind measurement together with more wind turbine aero-elastic simulations to answer many of the remaining open research questions.

The conclusions and future directions from WP2 as taken from the final report are summarized below: 
- A process methodology has been established to process high frequency wind measurement data for deriving turbulence parameters for carrying out load simulations. A data cleaning procedure has also been determined.

- The Mann model parameters and associated turbulence intensities together with other site parameters such as air density, wind shear exponent, etc., have been derived for several sites covering onshore, nearshore, and offshore locations. These parameters were used for generating turbulence boxes for load sensitivity studies.

- Based on the study, it was decided to implement a low-frequency cut-off wherein the spectral fitting does not agree well, i.e, the Mann model does not capture the lowfrequency part of the spectrum. To understand the influence of this low-frequency cut-off on fatigue loads, a simplified sensitivity study has been carried out. This turned out that the effect is not significant, i.e., from a $1-\mathrm{Hz}$ damage-equivalent load (DEL) point of view, the influence is only around $+/-10 \%$ on the major load components, and from a lifetime DEL point of view, the effect is negligible. This justifies the implementation of the low-frequency cut-off. However, the low-frequency part of the spectrum, its consequence on the turbulence parameters and eventually on loads may be investigated more in detail.

- Further, in certain cases, a spectral peak is seen at high frequencies, mostly at around the structural frequency of the boom (probably caused by the vibrational mode of the boom in which the sensors are mounted). For these cases, it was also decided to implement a high-frequency cut-off in order not to distort the spectrum due to the presence of this high-frequency peak.

- During the analysis, it was observed that detrending is an important topic, which affects the turbulence parameter results derived based on spectral fitting. And hence, a more detailed analysis on this direction is needed, which is suggested as a future study.

- As a future study, it is suggested to segregate the stability conditions sector-wise, by taking directionality into account. This would be a more realistic representation for future analysis.

- In the case of Mann model parameter derivation from spectral fitting, it is suggested to quantify the spectral fitting errors as a future study in order to address if the site is following the Mann model or not.

- The Mann model spectral fitting algorithm may be improved by implementing weighting factors for different aspects such as turbulence intensity. This would enable the optimization algorithm to preserve the specific turbulence intensity levels and thereby a better representation of the site stability parameters.

Below are a few samples of the data collected during WP2. 


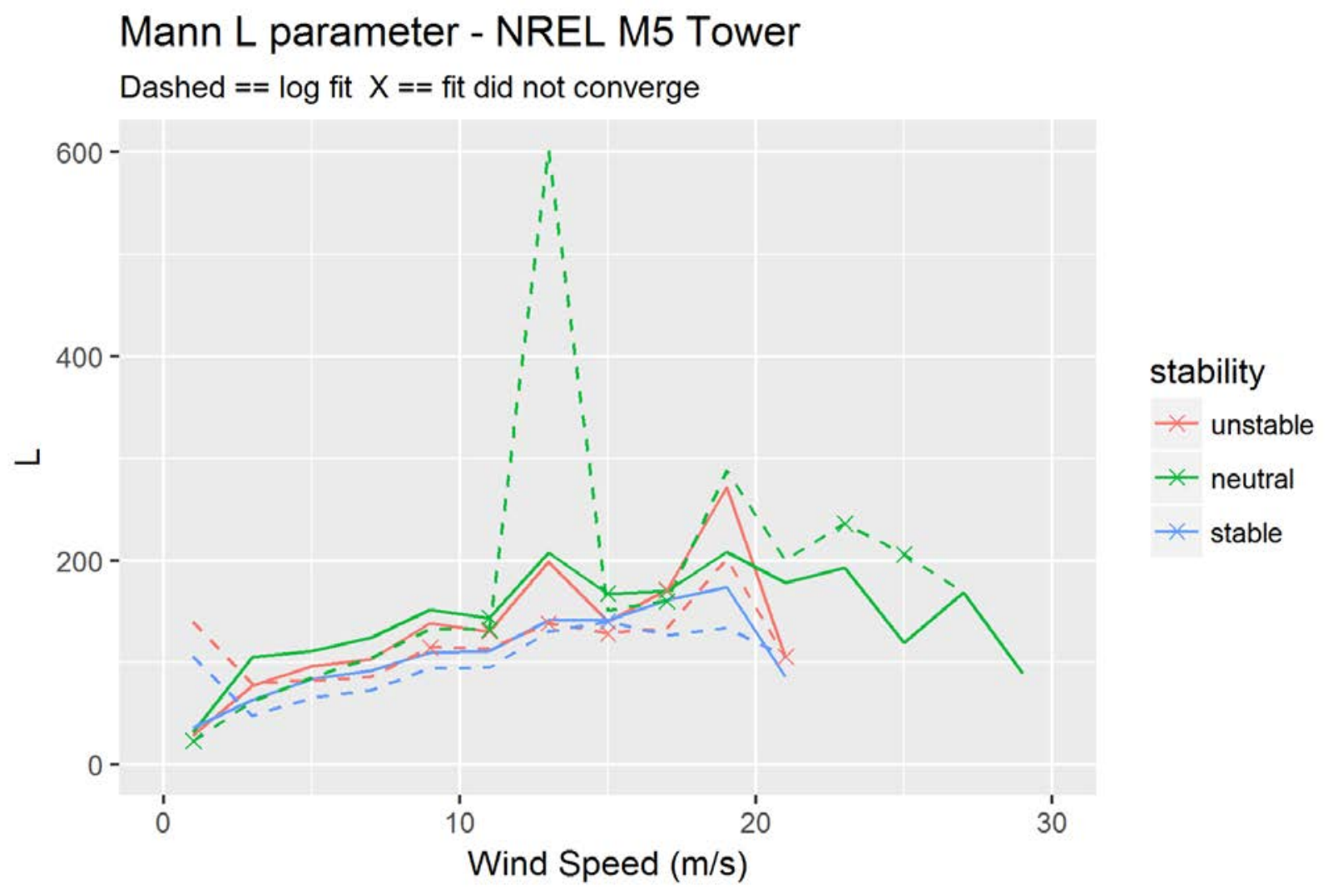

\section{Turbulence Intensity $50 \%$ and $90 \%$ Levels}

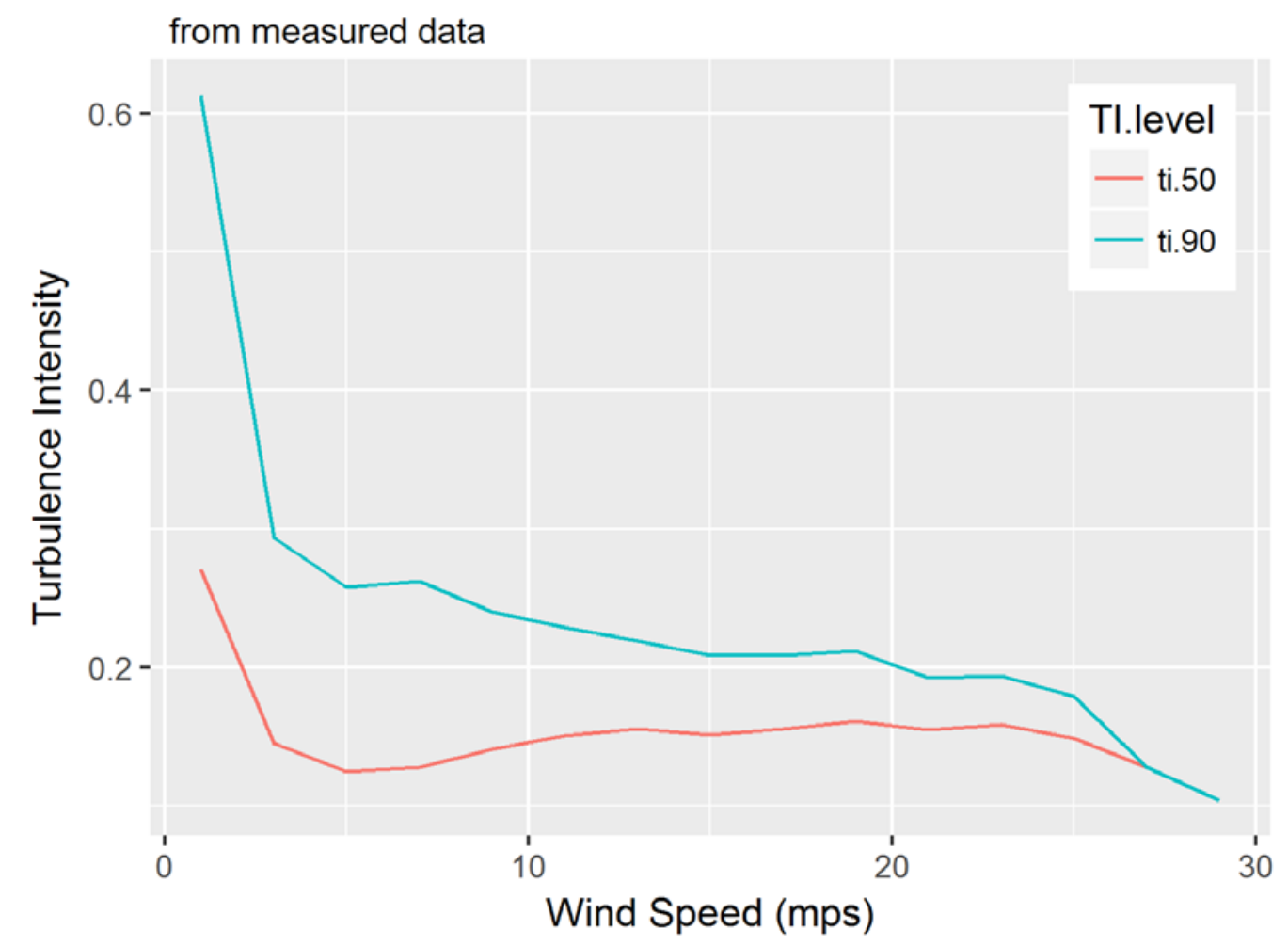




\section{TI calculated from Mann Parameters}

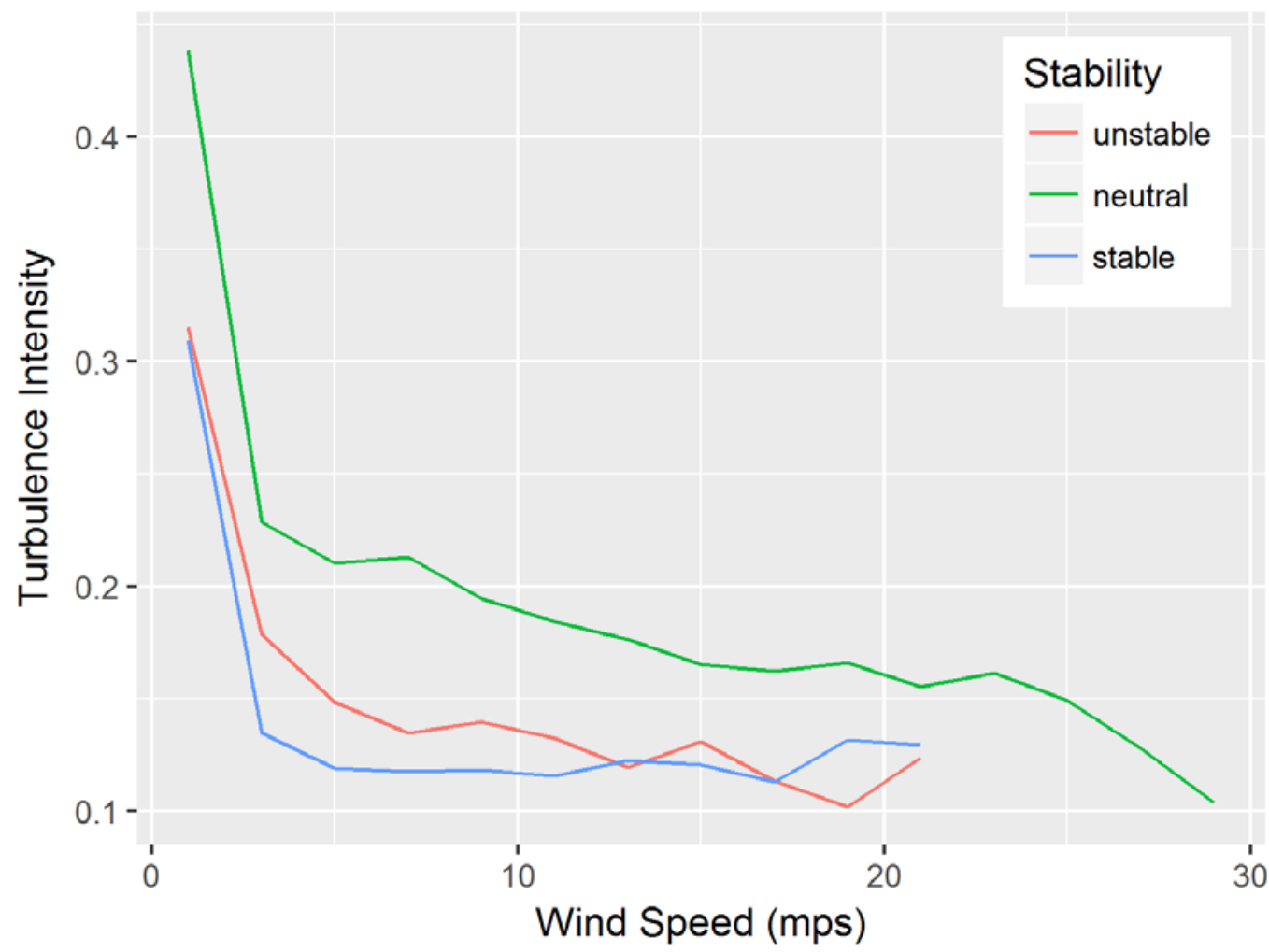

The conclusions and future directions from WP3 as taken from the final report are summarized below:

- Stability sensitivity - from the stability sensitivity investigations, for certain sites, it seems that the stability influence is large, especially for the tower loads. In the case of some of the results, the influence is masked by having different turbulence intensity levels between the IEC baseline and the stability-affected loads due to the turbulence scaling issue in the aero-elastic codes. As there are no standardized turbulence scaling methods in existence to achieve the targeted turbulence intensity levels without affecting the spectra and its statistics, it is recommended to investigate as a future study to conclude and suggest a common approach, which is more correct than the existing ones.

- Wake sensitivity - a primitive and limited wake influence study shows that the above observation from the stability study may be neutralized due to the dominating influence of higher turbulence intensity. This should be investigated further. As a first step, a similar study could be replicated at more sites and if a common conclusion can be arrived, a follow-up study would be beneficial, especially looking at the wake by taking into account the dynamic wake meandering (DWM) model or to suggest an intermediate approach between the Frandsen model and DWM model.

- Influence of Mann model vs. Veers method - the analysis show that more investigations are needed by replicating the analysis for the other stability conditions and other sites.

- Energy spectra and coherence - it is suggested to investigate if the Mann model spectra derived has preserved the coherence information as measured in the site. This will be 
carried out as a future study. Further, it is also suggested to carry out the load simulations using the measured spectra and coherence information without making any spectral fits.

Below are the load and output results for the NREL under WP3.
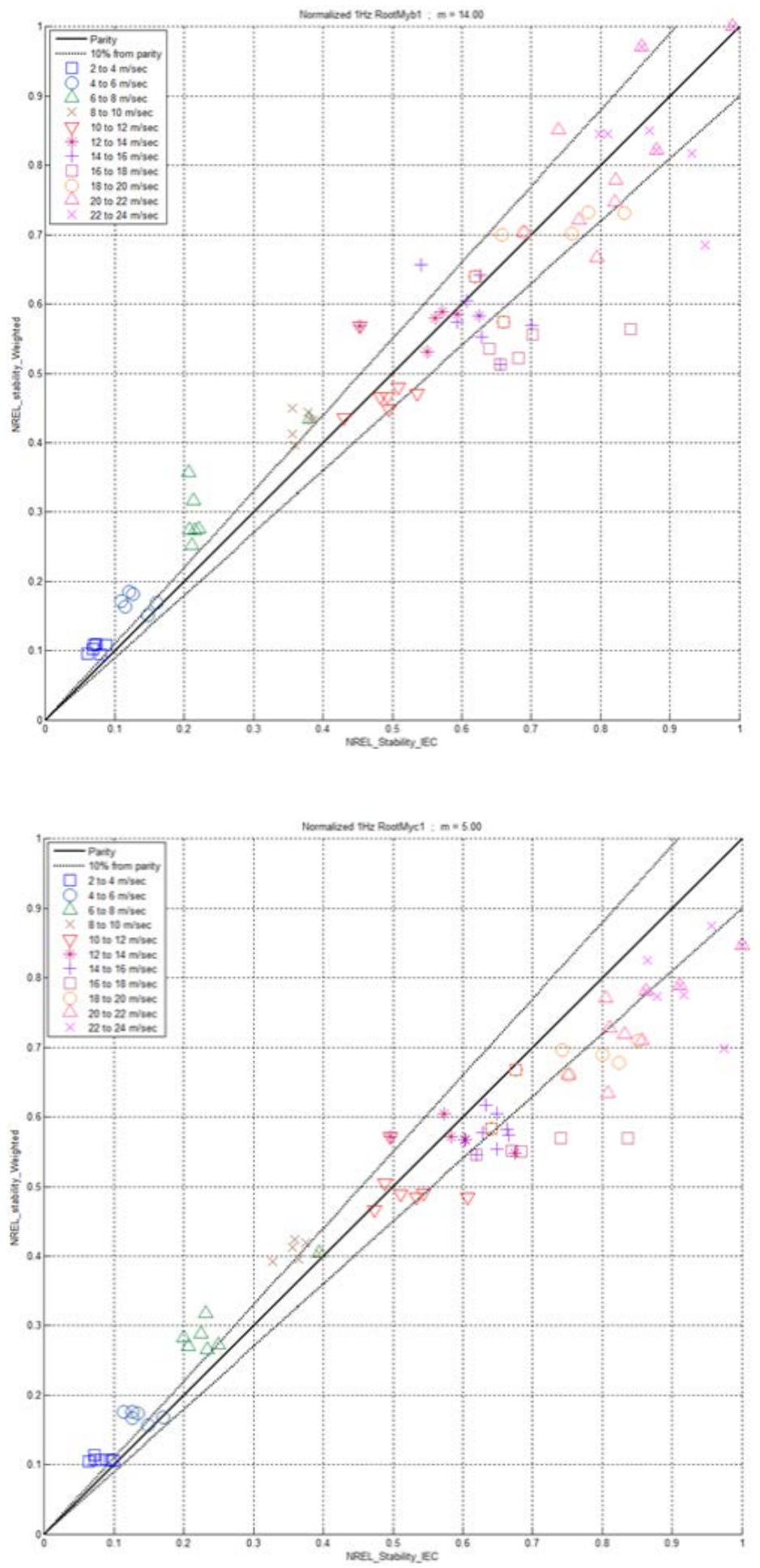
The final project conclusions as taken from the final report are summarized below:

- A data processing methodology has been developed

- Mann model fitting methodology recommendations such as frequency cut offs are suggested

- Stability seems to affect the fatigue loading, however, the wake seems to decrease this effect. As the wake model used for the investigations is crude and used a more conservative turbine spacing of five times the rotor diameter, a more realistic wake study (probably considering seven or ten times the diameter) would neutralize the overshadowing of wake seen on fatigue loads. This will likely result in a scenario that taking into account stability would be important for the fatigue loads.

- Present industry practice for the wind farm design is to consider the worst wake situation wind climate for load calculations. In this scenario, the stability consideration may not be important as seen today. However, if the industry is moving towards optimized wind farm lay out and carrying out load calculations for all the turbine positions by taking the turbine-specific wind climate into account, the wind climate should likely include the stability consideration appropriately.

- Turbulence intensity seems to be a major driver for the load impact as expected.

- The larger Gamma values from the Mann model seem to drive the blade flap-wise moment apart from the turbulence intensity.

\section{Subject Inventions Listing:}

None

\section{Report Date:}

August 30, 2018

\section{ROI \#:}

None

Responsible Technical Contact at Alliance/NREL:

Jason Jonkman/Paul Veers

Name and Email Address of POC at Company:

Mersudin Bajric, mersudin.bajric@dnvgl.com

\section{DOE Program Office:}

Wind \& Water Power Technologies

This document contains NO confidential, protectable, or proprietary information. 